Im Journal Club referieren

und kommentieren diese

Experten für Sie die

wichtigsten Arbeiten

aus der internationalen

Fachliteratur.
Prof. Dr. med.

Thomas

Katzorke,

Essen

\section{Trisomie aus dem Blut der Mutter diagnostizieren?}

\author{
Seit Kurzem wird der Wert von zellfreier (cf) DNA aus mütterlichem Plasma für \\ die nicht invasive pränatale Trisomie-Diagnostik erforscht. Ein relativ neues \\ Verfahren ist die chromosomenselektive Sequenzierung der cfDNA.
}

W enn bei einem Ungeborenen eine Trisomie besteht, ist der Anteil des betroffenen Chromosoms im mütterlichen Plasma leicht erhöht. Eine solche Verschiebung konnte in Studien durch das Massively Parallel Shotgun Sequencing (MPSS) nachgewiesen werden. Bei dieser Methode müssen jedoch viele Millionen DNA-Fragmente sequenziert werden. Ein weniger aufwendiges Verfahren, die Digital Analysis of Selected Regions (DANSR), beschränkt sich auf die selektive Sequenzierung der fraglichen Chromosomen. Sensitivität und Spezifität der DANSR für die Trisomie 21 und 18 wurden nun in einer Studie überprüft.

Dafür wurden Blutplasmaproben aus der 11. bis 13. Gestationswoche nachträglich per DANSR ausgewertet. Die Proben stammten von 300 euploiden Schwangerschaften und jeweils 50 Trisomie-21- und Trisomie-18-Schwangerschaften. Dem Untersuchungslabor wurden Risikofaktoren der Schwangeren, aber nicht der Karyotyp des Feten mitgeteilt. Auf Basis der cf-DNAAnalyse wurde mithilfe eines speziellen Algorithmus (FORTE) für jeden Fetus das Risiko einer Aneuploidie errechnet.

Bei allen Trisomie-21-Fällen ergab sich ein Risikoscore von $\geq 99 \%$ für eine Trisomie 21 und von $\leq 0,01 \%$ für eine Trisomie 18. Ebenso lag bei allen Trisomie-18Schwangerschaften der Risikoscore für eine Trisomie 21 bei $\leq 0,01 \%$; der Risikoscore für eine Trisomie 18 erreichte in 47 Fällen $\geq 99 \%$, in je einem Fall betrug er $98,8 \%, 88,5 \%$ bzw. nur $0,11 \%$. Von den 300 euploiden Schwangerschaften konnten 297 ausgewertet werden. Der Risikoscore für eine Trisomie 21 war bei allen $\leq 0,01 \%$; der für eine Trisomie 18 betrug 295-mal $\leq$ $0,01 \%$, einmal $0,04 \%$ und einmal 0,23\%. Damit hatte die cf-DNA-Sequenzierung eine Sensitivität von $100 \%$ für eine Trisomie 21 (50/50) und von 98\% für eine Trisomie 18 (49/50). Die Spezifität der Pränataldiagnostik lag bei 100\% (297/297).

Die chromosomenselektive Sequenzierung ist eine vielversprechende Methode, um fetale Trisomien 21 oder 18 bereits im ersten Trimenon mittels cfDNA aus mütterlichen Blut nachzuweisen, so die Autoren. In der Studie konnten alle Trisomie 21- und 98\% der Trisomie-18-Fälle von euploiden Schwangerschaften unterschieden werden.

Dr. Beate Schumacher

Ashoor G et al. Chromosome-selective sequencing of maternal plasma cell-free DNA for first-trimester detection of trisomy 21 and trisomy 18. Am J Obstet Gynecol 2012; 206:322.e1-5

Kommentar: Seit Jahrzehnten wird an Verfahren der nicht invasiven, zyto- oder molekulargenetischen Pränataldiagnostik gearbeitet. Nun scheint es, als sei mithilfe des Next Generation Sequencing der Durchbruch gelungen. Die Studie von Ashoor stellt eine Methode vor, die sich in einigen technischen Details vom „Praena Test ${ }^{\circledR}$ " unterscheidet. Dieser soll nach Angaben der Firma "LifeCodexx" in Kürze auf dem deutschen Markt verfügbar sein.

Welchen Platz werden die neuen genetischen Tests am mütterlichen Blut im Ensemble der etablierten pränataldiagnostischen Maßnahmen einnehmen? Hier sind noch viele
Fragen offen. Wird sich der Test unter den rauen Bedingungen des klinischen Alltags als ebenso aussagestark erweisen wie in hochkontrollierten Pilotstudien? Oder: Wird es dabei bleiben, dass immer das nicht invasive Ersttrimester-Screening (NT \pm biochemische Parameter) vorgeschaltet wird? Das würde bedeuten, dass der genetische Test an mütterlichem Blut im Wesentlichen auf ein Kollektiv mit hohem fetalem Aneuploidierisiko beschränkt bliebe. Haben wir es eigentlich mit einem diagnostischen Test oder mit einem Screeningverfahren zu tun? Im ersteren Fall müsste man konsequenterweise auch darüber Rechenschaft geben, ob denn allein auf Basis des Testergebnisses ein Schwangerschaftsabbruch erfolgen könnte. Wer kommt ferner für die Kosten des Bluttestes auf? Wird es nur finanziell gutgestellten Schwangeren vorbehalten sein, die Risiken einer invasiven Diagnostik zum Trisomieausschluss zu vermeiden? Und was sind die gesellschaftlichen Implikationen des Testes, vor allem wenn er allgemein verfügbar (i.e. fremdfinanziert) würde und - was die Methodik hergibt - an Aussagebreite gewinnt, etwa durch Ausdehnung auf andere genetische Störungen. In den seriösen Populärmedien nimmt diese Frage jetzt schon großen Raum in der Diskussion ein.

So ist derzeit noch nicht zu abzusehen, ob der neue Test die Pränatalmedizin umwälzen wird oder ob er sich einzureihen hat als eine unter vielen, differenziert einzusetzenden Methoden. Aber eines wird er nicht tun, wie auch die Autoren betonen: die bisherige Ersttrimester-Diagnostik ersetzen. Nicht nur, dass diese inzwischen eine Detektionsrate von $\geq 95 \%$ für die häufigen Aneuploidien erreicht. Vielmehr hat sich die Ersttrimesteruntersuchung längst von einem reinen Aneuploidiescreening zu einem komplexen Diagnoseinstrument emanzipiert, dessen Aussagen weit über die Frage der An- oder Abwesenheit einer Trisomie hinausreichen. Dr. med. Dieter Meschede 